\title{
Technical standards for respiratory oscillometry
}

\author{
Gregory G. King ${ }^{1}$, Jason Bates ${ }^{2}$, Kenneth I. Berger ${ }^{3}$, Peter Calverley ${ }^{4}$, Pedro \\ L. de Melo $\mathbb{1 0}^{5}$, Raffaele L. Dellacà (10 ${ }^{6}$, Ramon Farré ${ }^{7,8}$, Graham L. Hall $^{9}$, \\ Iulia Ioan (10,11, Charles G. Irvin ${ }^{2}$, David W. Kaczka (1) ${ }^{12}$, David A. Kaminsky², \\ Hajime Kurosawa ${ }^{13}$, Enrico Lombardi ${ }^{14}$, Geoffrey N. Maksym (i) ${ }^{15}$, \\ François Marchal ${ }^{10,11}$, Beno W. Oppenheimer ${ }^{3}$, Shannon J. Simpson ${ }^{9}$, \\ Cindy Thamrin (10) ${ }^{1}$, Maarten van den Berge ${ }^{16}$ and Ellie Oostveen ${ }^{17}$
}

@ERSpublications

With increasing clinical and research use of oscillometric measurements of respiratory system resistance and reactance, an update to the 2003 technical standards has been developed by an ERS task force of international experts http://bit.ly/2XBJ7PF

Cite this article as: King GG, Bates J, Berger KI, et al. Technical standards for respiratory oscillometry. Eur Respir J 2020; 55: 1900753 [https://doi.org/10.1183/13993003.00753-2019].

ABSTRACT Oscillometry (also known as the forced oscillation technique) measures the mechanical properties of the respiratory system (upper and intrathoracic airways, lung tissue and chest wall) during quiet tidal breathing, by the application of an oscillating pressure signal (input or forcing signal), most commonly at the mouth. With increased clinical and research use, it is critical that all technical details of the hardware design, signal processing and analyses, and testing protocols are transparent and clearly reported to allow standardisation, comparison and replication of clinical and research studies. Because of this need, an update of the 2003 European Respiratory Society (ERS) technical standards document was produced by an ERS task force of experts who are active in clinical oscillometry research.

The aim of the task force was to provide technical recommendations regarding oscillometry measurement including hardware, software, testing protocols and quality control.

The main changes in this update, compared with the 2003 ERS task force document are 1) new quality control procedures which reflect use of "within-breath" analysis, and methods of handling artefacts; 2) recommendation to disclose signal processing, quality control, artefact handling and breathing protocols (e.g. number and duration of acquisitions) in reports and publications to allow comparability and replication between devices and laboratories; 3) a summary review of new data to support threshold values for bronchodilator and bronchial challenge tests; and 4) updated list of predicted impedance values in adults and children.

This article has supplementary material available from erj.ersjournals.com

This document was endorsed by the ERS Executive Committee on 10 November 2019.

Received: 14 April 2019 | Accepted after revision: 15 Oct 2019

Copyright @ERS 2020 


\section{Overview of the document}

There is increasing research on oscillometry, and increased interest and feasibility in its clinical application. Respiratory oscillometry measures the mechanical properties of the respiratory system (upper and intrathoracic airways, lung tissue and chest wall) during quiet tidal breathing, by the application of small pressure or flow oscillations (input or forcing signal), most commonly at the mouth.

Although the fundamental principles of oscillometry measurement are essentially the same for all devices, there are differences in hardware, data acquisition and signal processing and analyses and breathing protocols that may lead to differences in impedance measurements. Furthermore, oscillometry is fundamentally a different measurement to traditional lung function measurements, i.e. spirometry and lung volumes.

Oscillometry has been applied across a wide range of clinical and research settings, but these important topics are not covered in this document. The aim of the present document is to highlight technical factors, hardware, software and factors during patient testing that potentially affect oscillometric measurements. Addressing these factors is critical for standardisation and obtaining accurate oscillometry measurements of the highest standards. Consequently, it is critical that all technical details of the hardware design, signal processing and analyses, and testing protocols are transparent and clearly reported to allow standardisation, comparison and replication of clinical and research studies.

This task force document contains general recommendations about oscillometric measurement including hardware, software, testing protocols and quality control. Given the wide range of scenarios in which oscillometry can be applied, many recommendations are general, although some are more specific where appropriate. A summary of technical recommendations and clinical testing of oscillmetry is detailed in table 1. The main differences of this update, compared with the 2003 European Respiratory Society (ERS) task force document [1] are detailed in table 2.

\section{Introduction}

Oscillometry (also known as the forced oscillation technique or "FOT") was first described in 1956 [2]. Usually, this technique is used to measure the mechanical properties of the respiratory system in a passive manner, i.e. manoeuvres such as forced expiration are not required. Oscillations can be superimposed over spontaneous tidal breathing or respiratory support ventilation and can be highly utilised in a number of clinical settings that routine clinical tests cannot, including in young children and during mechanical ventilation.

In oscillometry testing, a stimulus is applied to the respiratory system at the mouth. The input signal is either the pressure or flow oscillation, and the response (in terms of flow or pressure, respectively) is measured. The ratio of oscillatory pressure to oscillatory flow generated from this oscillatory stimulus is used to calculate input impedance, and represents the total mechanical properties of the respiratory system. The limitation of this representation of the respiratory system is that it is assumed to behave in a linear manner, whereas there is likely nonlinear behaviour even in healthy lungs (primarily in the proximal and upper airways) and even more so in diseased lungs. Furthermore, ventilation is heterogeneous in healthy lungs and much more so in disease, which also affects this relationship. The

Affiliations: 'Dept of Respiratory Medicine and Airway Physiology and Imaging Group, Royal North Shore Hospital and The Woolcock Institute of Medical Research, The University of Sydney, Sydney, Australia. ${ }^{2}$ Dept of Medicine, Pulmonary/Critical Care Division, University of Vermont, Larner College of Medicine, Burlington, VT, USA. ${ }^{3}$ Division of Pulmonary, Critical Care, and Sleep Medicine, NYU School of Medicine and André Cournand Pulmonary Physiology Laboratory, Belleuve Hospital, New York, NY, USA. ${ }^{4}$ Institute of Ageing and Chronic Disease, University of Liverpool, Liverpool, UK. ${ }^{5}$ Institute of Biology and Faculty of Engineering, Department of Physiology, Biomedical Instrumentation Laboratory, State University of Rio de Janeiro, Rio de Janeiro, Brazil. ${ }^{6}$ Dipartimento di Elettronica, Informazione e Bioingegneria - DEIB, Politecnico di Milano University, Milano, Italy. ${ }^{7}$ Unitat de Biofísica i Bioenginyeria, Facultat de Medicina, Universitat de Barcelona-IDIBAPS, Barcelona, Spain. ${ }^{8}$ CIBER de Enfermedades Respiratorias, Madrid, Spain. ${ }^{9}$ Children's Lung Health, Telethon Kids Institute, School of Physiotherapy and Exercise Science, Curtin University, Perth, Australia. ${ }^{10}$ Dept of Pediatric Lung Function Testing, Children's Hospital, Vandoeuvre-lès-Nancy, France. ${ }^{11}$ EA 3450 DevAH - Laboratory of Physiology, Faculty of Medicine, University of Lorraine, Vandoeuvre-lès-Nancy, France. ${ }^{12}$ Depts of Anesthesia, Biomedical Engineering and Radiology, University of lowa, lowa City, IA, USA. ${ }^{13}$ Dept of Occupational Health, Tohoku University School of Medicine, Sendai, Japan. ${ }^{14}$ Pediatric Pulmonary Unit, Meyer Pediatric University Hospital, Florence, Italy. ${ }^{15}$ School of Biomedical Engineering, Dalhousie University, Halifax, NS, Canada.

${ }^{16}$ University of Groningen, University Medical Center Groningen, Dept of Pulmonary Diseases, Groningen, The Netherlands. ${ }^{17}$ Dept of Respiratory Medicine, Antwerp University Hospital and University of Antwerp, Antwerp, Belgium.

Correspondence: Gregory G. King, Sydney University, The Woolcock Institute of Medical Research, 431 Glebe Point Rd, Glebe, NSW 2037, Australia. E-mail: ggkawoolcock.org.au 
TABLE 1 Summary of technical recommendations and clinical testing of oscillometry

Section

\begin{tabular}{|c|c|}
\hline \multicolumn{2}{|l|}{ Technical recommendations } \\
\hline $\begin{array}{l}\text { New test loads should be developed: a dynamic test load that } \\
\text { simulates patient breathing and a static load that includes } \\
\text { elastic and inertive components }\end{array}$ & $\begin{array}{l}\text { Technical recommendations and } \\
\text { standards for manufacturers }\end{array}$ \\
\hline $\begin{array}{l}\text { Verifications should be performed daily and publications } \\
\text { should report the input frequencies at which verifications } \\
\text { are performed, the resistive loads used and the acceptable } \\
\text { tolerances. The recommended tolerance for the } \\
\text { verification is } \leqslant \pm 10 \% \text { or } \pm 0.1 \mathrm{hPa} \cdot \mathrm{s} \cdot \mathrm{L}^{-1} \text {, whichever is } \\
\text { greater. The test loads should cover the range of } Z_{\mathrm{rs}} \\
\text { encountered in normal oscillometry use: adults } \\
\sim 15 \mathrm{hPa} \cdot \mathrm{s} \cdot \mathrm{L}^{-1} \text {; children } \sim 40 \mathrm{hPa} \cdot \mathrm{s} \cdot \mathrm{L}^{-1}\end{array}$ & $\begin{array}{l}\text { Technical recommendations and } \\
\text { standards for manufacturers }\end{array}$ \\
\hline $\begin{array}{l}\text { Details on signal processing for generation of impedance } \\
\text { indices, and their validations, should be published or be } \\
\text { made freely available from the relevant laboratories, in } \\
\text { references and from device manufacturers }\end{array}$ & Signal processing for oscillometry \\
\hline $\begin{array}{l}\text { Coherence should not be used to exclude data points. There } \\
\text { are a number of quality control methods that can be used } \\
\text { which should be formalised and disclosed by laboratories, } \\
\text { in publications and from device manufacturers }\end{array}$ & Use of coherence \\
\hline \multicolumn{2}{|l|}{ Clinical testing } \\
\hline $\begin{array}{l}\text { Reference values and cut-offs for bronchial challenge tests } \\
\text { should be assessed for the local population, which would } \\
\text { also be oscillometry device specific }\end{array}$ & Bronchial challenge testing \\
\hline $\begin{array}{l}\text { Ensure acquisition of sufficient artefact-free replicates, at } \\
\text { the time of testing. } 30 \text {-s acquisitions are recommended for } \\
\text { adults, which allows recording over at least three breaths; } \\
16 \text {-s acquisitions are recommended for children aged } \\
<12 \text { years. The coefficient of variation between replicates is } \\
\text { suggested to be } \leqslant 15 \% \text { for children and } \leqslant 10 \% \text { for adults }\end{array}$ & $\begin{array}{l}\text { Minimum number of technically } \\
\text { acceptable replicate measurements }\end{array}$ \\
\hline $\begin{array}{l}\text { Oscillometry testing should precede tests requiring deep } \\
\text { breaths le.g. exhaled nitric oxide, spirometry, diffusing } \\
\text { capacity) and allow a standardised length of time during } \\
\text { which deep breaths are withheld, before performing } \\
\text { oscillometry }\end{array}$ & Effect of volume history \\
\hline $\begin{array}{l}\text { The recommended thresholds for positive bronchodilator } \\
\text { responses in both children and adults is }-40 \% \text { in } R_{\mathrm{rs}_{5}} \\
+50 \% \text { in } X_{\mathrm{rs}_{5}} \text { and }-80 \% \text { in } \mathrm{AX} \text {. } \mathrm{z} \text {-scores are recommended } \\
\text { for future definition of a significant response, which will } \\
\text { require data of bronchodilator responses in healthy } \\
\text { populations }\end{array}$ & Bronchodilator responses \\
\hline $\begin{array}{l}\text { Patient acquisition protocols, e.g. duration of recording, } \\
\text { replicates, should be reported in the laboratory reports } \\
\text { and research publications }\end{array}$ & Reporting of results \\
\hline
\end{tabular}

most common and practical way to apply a forcing oscillation to the respiratory system is via the airway opening. Although there are other ways of applying a forcing oscillation to the respiratory system (for instance oscillating the chest wall [2]), this document only discusses oscillometry where signals are applied at the airway opening, as this is the most frequently encountered approach.

Pressure oscillations in the frequency range of $4-50 \mathrm{~Hz}$ are commonly generated by a loudspeaker. Lower frequencies (i.e. $<4 \mathrm{~Hz}$ and as low as $\sim 0.5 \mathrm{~Hz}$ ) may be used, usually being generated by a piston-type mechanical device [3] or pneumatic proportional solenoid valves [4] or loudspeaker. However, lower frequencies require the suspension of spontaneous breathing [5], which may be difficult or impossible in many patient populations. Hence, discussion of low-frequency techniques is minimal in this document. Excitation frequencies $>35 \mathrm{~Hz}$ are easily produced by woofer speakers or by an interrupter valve [6], and may be used under certain conditions, to assess the acoustic or mechanical properties of the large airways 
TABLE 2 Main differences between current and previous European Respiratory Society technical standards for oscillometry [1]

\section{New/updated technical recommendations and standards}

The ideal forcing frequency when applied to spontaneous breathing is $\geqslant 4 \mathrm{~Hz}$ (changed from $\geqslant 2 \mathrm{~Hz}$ )

Not using coherence function for quality control and use of CoV $\leqslant 10 \%$ in adults and $\leqslant 15 \%$ in children

The data supporting the thresholds that define bronchodilator responsiveness by oscillometry have been updated (not defined in 2003). The recommended thresholds for both children and adults is $-40 \%$ in $R_{\mathrm{rS}_{5}},+50 \%$ in $X_{\mathrm{rs}_{5}}$ and $-80 \%$ in $\mathrm{AX}$. z-scores are recommended for future definition of a significant response

For manufacturers (commercial and non-commercial) to report device accuracy for measuring test loads

Test loads would ideally include inertive and elastic components

Report testing procedures and protocols, and quality control parameters in clinical laboratory reports and in research papers

Oscillometry should be performed before tests which require a deep breath, e.g. spirometry, exhaled nitric oxide, and after a standardised period during which deep breaths are withheld. The order of tests and period of withholding deep breaths should be reported

Modern analysis tools allow removal of entire breaths affected by artefact, so that an acquisition may remain technically acceptable, as long as there are at least three breaths remaining in that acquisition

Reference articles (supplementary table E1) have been updated. In adults, two out of six were retained and five newer reference papers were added. In children, two out of nine were retained and 10 newer reference papers for school-aged children and one for preschool-aged children were added

Threshold values for bronchial challenge testing, which would be device-specific, should be developed for local populations

Recommendations that were not included in the current document

Input peak pressure upper limit (still valid)

Use of 4-30 Hz frequency range to explore frequency dependence of $Z_{\text {rs }}$ (still valid)

Clinical application in respiratory diseases and potential for differentiating disease from non-disease Inot within the scope of the current task force

CoV: coefficient of variability; $R_{\mathrm{rs}_{5}}$ : resistance of respiratory system at $5 \mathrm{~Hz} ; X_{\mathrm{rs}_{5}}$ : reactance of respiratory system at $5 \mathrm{~Hz}$; $A X$ : area of reactance; $Z_{\mathrm{rs}}$ : respiratory system impedance.

and their walls. At present, such high frequencies are not commonly used in clinical settings, and are not discussed further.

Although forced oscillations are simple in principle to administer, there are potential sources of error and variation which include variations in patient breathing, bacterial filters, artificial airways, device hardware and signal analysis, data processing and quality control strategies. A technical standards document was published in 2003 [1]. Since then, there has been a large body of published research involving oscillometry in relation to improving the measurement technique as well as clinical studies, necessitating this update.

Key concepts of oscillatory mechanics of the respiratory system

Respiratory system impedance $\left(Z_{\mathrm{rs}}\right)$ assesses the relationship between pressure and flow changes during oscillatory flow in and out of the lungs. $Z_{\mathrm{rs}}$ has two basic components: resistance $\left(R_{\mathrm{rs}}\right)$ and reactance $\left(X_{\mathrm{rs}}\right)$ :

$$
Z_{\mathrm{rs}}=R_{\mathrm{rs}}+\mathrm{j} X_{\mathrm{rs}}(\mathrm{j} \text { is } \sqrt{-1} \text {; the unit imaginary number }) .
$$

The $X_{\mathrm{rs}}$ component of $Z_{\mathrm{rs}}$ can be further defined as:

$$
Z_{\mathrm{rs}}=R_{\mathrm{rs}}+\mathrm{j}\left(\omega I_{\mathrm{rs}}-E_{\mathrm{rs}} / \omega\right)
$$

where $I_{\mathrm{rs}}=$ respiratory system inertance and $E_{\mathrm{rs}}=$ respiratory system elastance and $\omega=2 \pi f$ and $f$ is the oscillation frequency.

$R_{\mathrm{rs}}$ may be largely interpreted as airway calibre. Thus, narrower and longer airways have higher resistances due to greater frictional pressure loss as air flows through them. In addition, $R_{\mathrm{rs}}$ is affected by the heterogeneous distribution of resistances and reactances (see later) across the airway tree, where increasing 
heterogeneity increases the effective resistance at any given frequency [7]. There are also contributions from the parenchymal tissues and chest wall to the effective $R_{\mathrm{rs}}$. Since $R_{\mathrm{rs}}$ reflects opposition to changes in flow, it is the component of $Z_{\mathrm{rs}}$ which is in phase with flow and increased resistance will decrease flow for a given pressure input. It will not cause a "time delay" (i.e. phase lag) in flow change, in relation to pressure change.

In contrast to resistance, $X_{\mathrm{rs}}$ represents pressures changes that are out of phase with flow, but in phase with volume changes. Therefore, $X_{\mathrm{rs}}$ has also been called the "out of phase" component or the "imaginary" component, due to the nature of its mathematical description described earlier, involving " $j$ ", the unit imaginary number. The term "imaginary part of impedance" is potentially confusing, and is best avoided in clinical settings. Therefore, reactance is the preferred term for this component of $Z_{\mathrm{rs}}$.

Reactance is comprised of both inertance and elastance. $E_{\mathrm{rs}}$, which is $1 /$ compliance, is a measure of the stiffness of the entire system (chest wall, lungs and airway walls) which, at commonly used oscillometry frequencies, includes compressibility of gas in the airways and alveoli. As volume changes, the resultant elastic forces cause pressure changes to lag behind flow changes (time delays or phase lags) and hence elastance causes reactance to be negative. Therefore, more negative reactance indicates greater elastance or stiffness under oscillatory (dynamic) conditions (according to the $Z_{\mathrm{rs}}$ equation). In addition, reactance is affected by the heterogeneous distribution of airway calibres and lung compliances across the airway tree, i.e. time constants (resistance $\times$ compliance) $[8,9]$. This typically occurs in obstructive airways diseases. Heterogeneity (of time constants) makes the effective elastance (and hence $X_{\mathrm{rs}}$ ) very sensitive to frequency (frequency-dependent). Increasing heterogeneity decreases the effective reactance (i.e. increases stiffness/ elastance) at any given frequency.

$I_{\mathrm{rs}}$ is an index of pressure losses mostly due to acceleration of the gas column in the central airways. Besides this airway component, which is determined by gas density and the ratio of airways length to surface area, $I_{\mathrm{rs}}$ also has a lung-chest wall component, which is determined by the ratio of their respective masses to the squared surface area. In normal circumstances, the lung-chest wall component of $I_{\mathrm{rs}}$ is small compared to the airway component. $I_{\mathrm{rs}}$ becomes significant at higher frequencies, where the bulk of gas and structures in the lung are oscillated at higher speeds. Inertance represents opposition to these accelerative forces, which act in the opposite direction $\left(180^{\circ}\right.$ out of phase) to elastance. Therefore, inertance causes pressure to lead ahead of flow oscillations, and causes reactance to be positive.

When the respective magnitudes of inertance and elastance are equal, the elastic contribution exactly equals the inertive contribution. Being in opposite directions they cancel each other out and reactance becomes zero. This point is termed resonant frequency $\left(f_{\text {res }}\right)$ and its corresponding frequency typically occurs in healthy adults at $\sim 8-12 \mathrm{~Hz}[10]$ and increases with decreasing age, where $f_{\text {res }}$ can be $>30 \mathrm{~Hz}$ in young children. Hence when $X_{\mathrm{rs}}=0, Z_{\mathrm{rs}}=R_{\mathrm{rs}}$. At frequencies above $f_{\text {res }}, X_{\mathrm{rs}}$ is positive in value because it is dominated by the apparent inertia of the gas and tissues.

Resistances, elastances and inertances of airways and subtending lung vary in magnitude, and are distributed in a variable manner within the lung, i.e. there is inherent heterogeneity in the respiratory system. This heterogeneous distribution of $R_{\mathrm{rs}}$ and $E_{\mathrm{rs}}$ properties in the lung explain an important mechanical characteristic of oscillometry; that of frequency dependence.

\section{Frequency dependence}

$R_{\mathrm{rs}}$, elastance and inertance (hence reactance) vary with frequency, i.e. they are frequency dependent (figure 1). Heterogeneity across the airway tree, tissue viscoelasticity, the airway wall shunt and pendelluft all contribute to frequency dependence. As frequencies decrease below $5 \mathrm{~Hz}, R_{\mathrm{rs}}$ increases rapidly while reactance becomes more negative as the mechanical properties of the lung (tissue viscoelasticity) and chest wall (elastance) dominate. As frequency increases within the commonly used frequency range $(4-50 \mathrm{~Hz})$, the lung and chest wall contributions diminish, and $R_{\mathrm{rs}}$ tends to be largely frequency independent in healthy adults and is dominated by the airway properties. In healthy children, $R_{\mathrm{rs}}$ continues to show negative frequency dependence. As described earlier, with increasing frequency, the apparent elastance continues to decrease, i.e. $X_{\mathrm{rs}}$ becomes less negative, as inertia begins to dominate $X_{\mathrm{rs}}$, i.e. positive frequency dependence.

In infants, $Z_{\mathrm{rs}}$ at a frequency $<1-2 \mathrm{~Hz}$ contains information on resistive and elastic properties of the tissue (lungs and chest wall) [11]. The contribution of the chest wall to $Z_{\mathrm{rs}}$ decreases with increasing frequency and increases with increasing age [12]. $R_{\mathrm{rs}}$ is dominated by nasal resistance in infants, because they are habitual nose breathers, and measurement therefore requires the use of a facial mask [13]. The presence of heterogeneous ventilation due to airways disease may affect frequency dependence. At frequencies between 5 and $15 \mathrm{~Hz}, Z_{\mathrm{rs}}$ contains information on airway resistance, and at frequencies $>50 \mathrm{~Hz}, Z_{\mathrm{rs}}$ is dominated by acoustic properties of the central airways, as well as the mechanical properties of the airway walls $[14,15]$. 
FIGURE 1 Diagram of frequency dependence of resistance and of reactance. Resonant frequency is the frequency at which reactance $\left(X_{\mathrm{rs}}\right)$ is 0 .

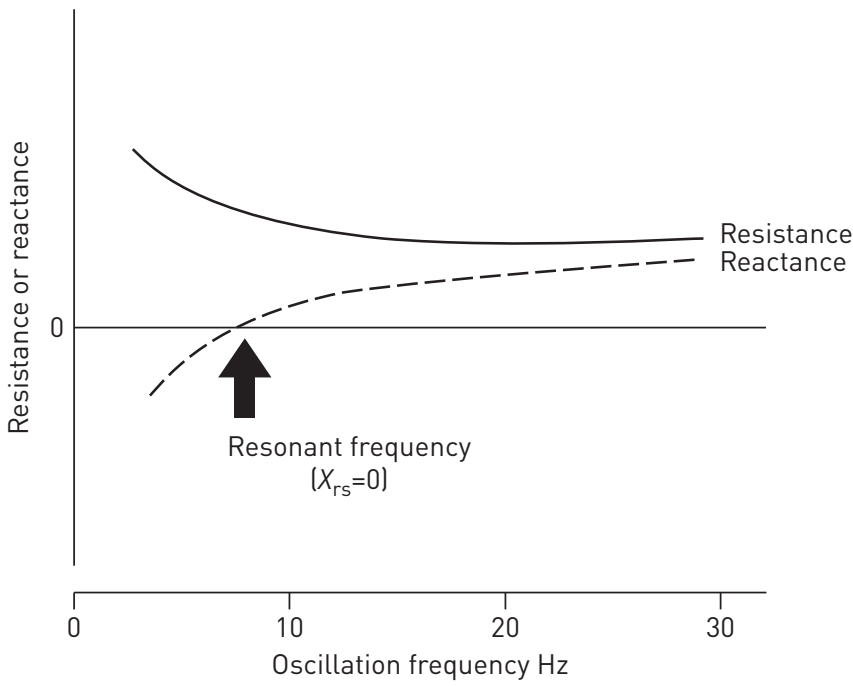

The negative frequency dependence of impedance may be conveniently represented as the difference between a high-frequency value of $R_{\mathrm{rs}}$ and a low-frequency value. However, the physiological information depends on the frequencies that are used. At normal tidal breathing frequency and below, frequency dependence of impedance reflects mostly the viscoelastic properties of the respiratory system tissues in healthy lungs. In disease, frequency dependence over normal tidal breathing frequency and higher, is enhanced by the increased heterogeneity of $R_{\mathrm{rs}}$ and $E_{\mathrm{rs}}$ due to increased variations in airway structure within a lung. Indeed, frequency dependence of $R_{\mathrm{rs}}$ in asymptomatic smokers with normal spirometry has been correlated with frequency dependence of compliance measured by oesophageal manometry [16]. The shunting of applied flow oscillations into the upper airways (cheeks, pharynx, etc.) arises from increased glottic and subglottic airway impedance and can also increase the overall frequency dependence of impedance $[3,17-21]$. Modelling studies $[19,22]$ suggest that $R_{\mathrm{rs}_{5-20}}$ may reflect the way in which the lung, behaving effectively as a single compartment (and with no involvement of tissue resistance) interacts with the upper airway structures into which flow oscillations are shunted. Hence, the physiological interpretation of frequency dependence remains uncertain, despite the common statement that parameters such as $R_{\mathrm{rs}_{5-20}}$ reflect small airway calibre. Unfortunately, there are as yet no published findings correlating pathology to frequency dependence. Therefore, this remains an area that requires further research.

\section{Clinical settings in which oscillometry is applied}

The oscillometry can be used in various clinical settings which include clinical lung function laboratories, field testing, home monitoring and intensive care. Oscillometry measurements have mostly been applied in airways diseases and paediatric lung diseases, where oscillometry may have the most widespread clinical application. There are a number of available commercial devices, as well as local bespoke devices. Different devices or modifications of the hardware, oscillatory signals or data analysis methods may make them more suitable for different applications, e.g. testing children or in the intensive care unit.

Low-frequency impedance (i.e. at frequencies encompassing typical breathing rates) can be measured in adults and infants, although this generally requires apnoea and relaxation of the chest wall muscles $[3,5]$. However, newer devices and signal processing techniques may allow measurement of low-frequency $Z_{\mathrm{rs}}$ during spontaneous breathing [23]. In infants, apnoea can be induced using the Hering-Breuer reflex, by delivering positive airway pressure via face mask. Oscillometry can also be acquired during quiet sleep if apnoea is not required, e.g. when single-frequency or higher frequency excitations are used. A wave tube technique is feasible as early as 1-3 days after birth [24-26].

$R_{\mathrm{rs}}, X_{\mathrm{rs}}, f_{\mathrm{res}}$ and other oscillometric indices provides data which complement "traditional" measurements such as spirometry, lung volumes, specific conductance and diffusing capacity. Oscillometric measurements provide information in patients who are unable to perform spirometry, e.g. who are poorly cooperative or frail. Oscillometry is an alternative to spirometry for conducting bronchial challenge testing in adults $[9,27-38]$. It may be particularly useful in children given the difficulties with spirometry at young age [39-45], although there are additional technical issues to consider [46, 47].

Oscillometry has been applied to occupational health screening and large adult and paediatric population studies [25, 26, 48]. The short testing times and ease of administration for subjects are potential 
advantages in this setting. Oscillometry can be more sensitive than spirometry for detection of airways disease due to occupational exposure [48-55], but this area requires further research.

Self-administered, daily oscillometry undertaken at home has been shown to be highly feasible in asthma and chronic obstructive pulmonary disease (COPD) patients [56-58]. The large volumes of daily data allow analysis of day-to-day variability using sophisticated time-series techniques that may potentially be clinically useful for the diagnosis of asthma, monitoring its response to therapy and clinical phenotyping [59]. In a COPD study, early intervention triggered by worsening of oscillometric indices was not associated with any differences in hospitalisation, or symptoms. However, there was a significant reduction in repeat hospitalisations, leading to significantly reduced healthcare costs [60].

The use of oscillometry also has potential for optimising mechanical ventilation in the intensive care unit or operating room [61-63], although this is still an area of ongoing research. Impedance has been measured from spectrally enhanced, ventilation waveforms, of which some may allow uninterrupted ventilation [64-68] or by modification of the hardware of the ventilator, without having to add components.

\section{Methods}

This task force was initiated by its two co-chairs Gregory King and Ellie Oostveen, who developed the aims and outline of the document and brought together the members of the task force. All attempts were made to include representatives from key research groups who have been active in publishing research involving oscillometry. The task force was initially a joint American Thoracic Society (ATS)/ERS project and subsequently an ERS project. The ATS withdrew support for the project at the end of 2018 due to slow progress.

The task force sought to produce a "state of the art" document bringing together the existing literature on oscillometry, so that the evidence to guide device design, quality control and measurement are presented in an integrated, coherent manner. In addition, we sought to identify areas of research needed to stimulate work and fill gaps in knowledge.

The task force comprised 21 international members, identified from their profiles in the international research literature in oscillometry. The members were representative of a wide range of countries: Australia, Belgium, Brazil, Canada, France, Italy, Japan, the Netherlands, Spain and USA. There was representation from paediatric (GLH, EL, SJS, CT and EO) and adult (GGK, JB, KIB, PC, PLM, RLD, RF, II, CGI, DWK, DAK, HK, GNM, FM, BWO, CT, MvdB, EO) oscillometry researchers; members included medical practitioners (GGK, KIB, PC, DWK, DAK, EL, BWO, MvdB); and all members were experienced in the practical use of oscillometry.

All members provided signed declarations of potential conflicts of interest, which were managed according to the ATS and ERS rules and were updated regularly and at the conclusion of the project. No members were excluded because of potential and disclosed conflicts of interest.

The individual sections were initially outlined by GGK and EO and agreed to by the task force at face-to-face meetings at the ATS and ERS congresses. The sections were assigned to working groups that were organised by GGK and EO. The literature searches for each section were conducted by the section authors, who used PubMed, Google Scholar and MEDLINE, limiting searches to English-language publications, but without limitation by year of publication.

The section drafts were collated, checked and edited for stylistic consistency by GGK. All sections were reviewed by all task force members. Specific issues relating to content were discussed by email and at face-to-face meetings. The task force met regularly between 2015 and 2018 at the ATS and ERS congresses, which were organised and chaired by GGK and EO, and were supported by both the ATS and ERS. Technical recommendations and standards of this document are a result of the task force interpretation of the current literature including the previous ERS technical standards (2003) or other widely used and accepted reference values and technical documents. In case of conflicting conclusions technical recommendations and standards had to have the agreement of at least 18 of the 21 task force members, including its chairs.

\section{System design and testing Input signals}

The physiological information contained in $Z_{\mathrm{rs}}$ is strongly dependent on the frequency range over which it is measured. For example, in healthy adult humans, the viscoelastic properties of the lung and chest wall tissues have a major influence on $Z_{\mathrm{rs}}$ at frequencies $<2 \mathrm{~Hz}$. Conversely, the flow resistance of the airway tree and the mass of the gas contained within it become important determinants of $R_{\mathrm{rs}}$ and $X_{\mathrm{rs}}$, 
respectively, at frequencies $>2 \mathrm{~Hz}$. Therefore, the oscillatory frequencies used to measure $Z_{\mathrm{s}}$ must be appropriate to the physiological function that is being investigated.

When determining $Z_{\mathrm{rs}}$ in spontaneously breathing humans, it is important to ensure that measurements of oscillatory pressure and flow are not significantly affected by unknown contributions from respiratory muscle activity. This can be achieved by having the lowest frequency in the applied oscillatory flow signal greater than the frequency of breathing and its harmonics. The practical lower limit of frequency of the oscillatory signal in spontaneously breathing adults is thus typically $4-5 \mathrm{~Hz}[1,69,70]$, although this may vary depending on the breathing frequency. Even so, noise correlated with the breathing signal may still be present [71], as may occur with the high respiratory rates of infants and toddlers, or during tachypnoea in adults. However, there are no data on the effect of respiratory rate on $R_{\mathrm{rs}}$ or $X_{\mathrm{rs}}$ in children. In adults, increased respiratory rates have been shown to increase $R_{\mathrm{rs}}$ and $X_{\mathrm{rs}}$ at $20 \mathrm{~Hz}$ in healthy and symptomatic subjects with normal spirometry [72].

The best signal-to-noise ratio for $Z_{\mathrm{rs}}$ measurements is obtained from a composite input signal consisting of the sum of discrete sinusoidal components with frequencies that provide good coverage over the entire frequency range of interest. Broadband waveforms may consist of small-amplitude random noise [73] or multiple sinusoids [71,74]. Excitation waveforms consisting of frequencies that are mutually prime, such that none is an integer multiple of any other [67,75], may be advantageous to minimise nonlinear distortions of impedance [76]. A convenient way to construct a mutually prime signal is to choose a desired fundamental frequency $($ e.g. $1 \mathrm{~Hz})$ and then include frequencies that correspond to prime numbers above this fundamental (e.g. $2,3,5,7 \ldots \mathrm{Hz}$ ) while not including the fundamental frequency itself i.e. 2$26 \mathrm{~Hz}$ pseudorandom signals. Some input signals are comprised of harmonics of a fundamental frequency, such as, for example, in the Jaeger impulse oscillometry system (IOS) (5 Hz) and i2M (2 Hz) devices. Harmonic distortion may occur with such waveforms if they induce large volume fluctuations in relation to the underlying breathing volume [64, 65, 76-78], especially when the respiratory system behaves in a substantially nonlinear fashion, i.e. in the presence of severe airflow obstruction or cyclic lung recruitment and derecruitment.

A comparison between oscillometry and IOS showed that $R_{\mathrm{rs}}$ measured by IOS was higher than by the $2-$ $26 \mathrm{~Hz}$ pseudorandom signals, which was directly related to the magnitude of $R_{\mathrm{rs}}$ [79]. In addition, there were subjectively similar differences between $R_{\mathrm{rs}}$ and frequency dependence between five different devices in healthy subjects, although these differences could have been due to differences between populations between centres [10].

The size of the sinusoidal components in a composite oscillatory signal should be such that there is sufficient signal-to-noise ratio at each frequency. The peak-to-peak excursion should be $\leqslant 0.3 \mathrm{kPa}$. A convenient example is to have equal power at each frequency [77] in the flow signal. The phases of the sinusoidal components should be chosen to minimise the peak-to-peak amplitude of the oscillatory signal, again to minimise the influence of nonlinear behaviour in the lung [74]. Details of signal composition, including signal-to-noise ratio, for all oscillometry devices should be publicly available.

\section{Technical recommendations and standards for manufacturers}

Calibration

Although a variety of configurations have been used [69], $Z_{\mathrm{rs}}$ is most commonly measured from the signals of two sensors placed at the mouthpiece level: a pressure transducer and a flowmeter based on a pneumotachograph with a differential pressure transducer. Sensor calibration ensures adequate corrections to compensate for inadequate device performance [80]. Firstly, on the assumption that a sensor is linear, static calibration should ensure correct gain and zero offset (taking into account possible temperature and position drifts). Secondly, dynamic calibration should compensate for a sensor's frequency response by digitally compensating $Z_{\mathrm{rs}}$ for the measured dynamic responses of the pressure and flow transducers or other instrumentation [81]. Dynamic calibration must ensure that the sensor signals are unaffected by mechanical vibrations at the desired oscillation frequencies. The common-mode rejection ratio (CMRR) of the pressure transducer attached to the pneumotachograph should be sufficiently high to minimise potential errors [82]. Alternatively, dynamic calibration procedures are available to compensate for both instrumentation frequency response and CMRR during oscillometric measurements [83]. As the dynamic response mainly depends on the physical dimensions of sensors and tubing [84], their frequency response usually does not change over time. Therefore, dynamic calibrations, in contrast to static calibrations of gain and zero offset, are not periodically required.

\section{Test load}

Achieving accurate measurements of $Z_{\mathrm{rs}}$ depends on many subtle details in the utilised hardware (sensors) and software (data processing). Procedures for characterising and calibrating for sensors responses are well 
defined, and if followed correctly should not result in significant errors in $Z_{\mathrm{rs}}$ measurements. By contrast, there is no unique data processing procedure (e.g. filtering, averaging, frequency analysis, data rejection criteria) that is ideal. Furthermore, there are many suitable numerical algorithms to implement these procedures. Manufacturers must provide documentation on the accuracy of their devices for measuring resistances and reactances of a static test load. The magnitude of that load impedance should be above the absolute value of $Z_{\mathrm{rs}}$ that is expected for any given patient or subject population in which the oscillometric device is to be used, including impedances encountered in children and adults during bronchial challenge testing. Therefore, it is recommended that test loads for adult testing be $\sim 15 \mathrm{hPa} \cdot \mathrm{s} \cdot \mathrm{L}^{-1}$ and for children $\sim 40 \mathrm{hPa} \cdot \mathrm{s} \cdot \mathrm{L}^{-1}$. Test loads of insufficient impedance may potentially lead to errors in measurement [85]. This test load should be supplied to the end-user for daily verification. At present, most test loads consist solely of a mechanically resistive component. Ideally, test loads should also include the elastic and inertial components of impedance.

Testing and comparing how different specific oscillometric devices behave in practice requires something more than ensuring that they meet general recommendations and how they measure static loads. Ideally, robust and accurate $Z_{\mathrm{rs}}$ measurements should require a patient simulator with well-controlled (but variable) mechanical properties, breathing patterns and artefacts [86]. Devices that simulate human physiology are common in medical device testing, especially for respiratory and gas flow measurements. For example, the ATS/ERS provide very specific recommendations for performance testing of spirometric devices, using devices that simulate high-fidelity flows typical of forced expiratory manoeuvres [87]. There are equivalent, albeit less specific recommendations for evaluating automatic continuous positive airway pressure devices [88] and mechanical ventilators [89], where using a well-characterised patient simulator as a reference is required. It is therefore equally important that such a test load be developed for objective assessment and comparison of oscillometry devices under realistic conditions.

\section{Verification by end-users}

End-users of commercial devices perform verification with impedance test loads and not calibration. Thus the following recommendations pertain to verification. Like other lung function equipment, verification with test loads should be performed daily or each day that the instrument is used, particularly if being used for clinical testing, as would be common practice for other lung function equipment in the pulmonary function laboratory [90]. More frequent verification may be needed during field testing when environmental conditions may change. Research articles should report how often device verifications occur, the mechanical characteristics of the load(s) verified, and the accepted tolerance of the verification. The recommended tolerance for the verification is $\leqslant \pm 10 \%$ or $\pm 0.1 \mathrm{hPa} \cdot \mathrm{s} \cdot \mathrm{L}^{-1}$, whichever is met first. If volume changes are to be measured in patients, then the accuracy of volume measurements should be verified against a calibration syringe and comply with ATS standards [87].

\section{System resistance and dead space}

The oscillometric system and the additional bacterial filter can add dead space and additional resistance to breathing. It is important to compensate for the bacterial filter resistance and combined dead space of filters and connectors for measurement accuracy and advisable to maintain low overall oscillometric system resistance and dead space to minimise potential effects on breathing pattern, which can increase tidal volume depending on measurement duration. The oscillometric system without a bacterial filter in place should have a resistance of $<1 \mathrm{hPa} \cdot \mathrm{s} \cdot \mathrm{L}^{-1}$ at $\leqslant 5 \mathrm{~Hz}$. There are numerous bacterial filters available for use with oscillometric systems, which will have a range of resistances. A single study showed differences in impedance measured with different filters by IOS in healthy adults [91]. A single study using the interrupter method in asthmatic children aged 4-16 years found a mean increase of $1.2 \mathrm{hPa} \cdot \mathrm{s} \cdot \mathrm{L}^{-1}$, but there was a wide variance of $\pm 3.4 \mathrm{hPa} \cdot \mathrm{s} \cdot \mathrm{L}^{-1}$ [92]. General recommendations are to use low-resistance filters of $<1 \mathrm{hPa} \cdot s \cdot \mathrm{L}^{-1}$ at $\leqslant 5 \mathrm{~Hz}$, to regularly measure the resistances of the filters and to compensate for the combined resistances of the oscillometric system + filter. Thus, the total equipment resistance of an oscillometric system should be $<2 \mathrm{hPa} \cdot \mathrm{s} \cdot \mathrm{L}^{-1}$ at $\leqslant 5 \mathrm{~Hz}$.

The recommended dead space for oscillometric devices used for testing adults is the same as for lung volume testing [90]: $<100 \mathrm{~mL}$ inclusive of the bacterial filter. Due to the mixing caused by the oscillatory flow, the effective dead space can be less than the physical volume. In preschool children, it should be $<70 \mathrm{~mL}$ inclusive of the bacterial filter [93].

\section{Signal processing for oscillometry}

Processing for oscillometric signals has major impacts on the overall accuracy of oscillometry measurements. Signal processing, either analogue, digital or a combination of the two, addresses six main tasks: 1) estimation of respiratory system impedance $\left(Z_{\mathrm{rs}}\right)$ from raw flow and pressure data; 2 ) filtering to reduce the noise that is always present in the signals; 3) compensation for the frequency response 
characteristics of the sensors and other components; 4) accounting for instrument dead space; 5) derivation of impedance parameters; and 6) calculation of indices for quality control of the measurements.

A description of signal analysis methods used in oscillometry to derive impedance parameters appears in the supplementary material.

In summary, in modern oscillometric devices, signal processing constitutes a critical component that has major effects on the performances of the overall system. Given the variety and the complexity of the algorithms used, manufacturers should make the information listed in table 3 available to the users, either by reporting them in research publications or making them available on request. Also, manufacturers are responsible for extensive validation of oscillometric devices in a variety of conditions, including simulations of both healthy and diseased conditions, and to disclose the validation set-ups and procedures and the values of test loads used.

\section{Testing protocols and procedures}

Unlike spirometry, oscillometry can be acquired using varying protocols and under varying breathing conditions, depending on the mechanical properties of interest. Oscillometric measurements are most commonly made during resting tidal breathing, but have also been made during larger volume excursions, e.g. from functional residual capacity to total lung capacity (TLC) or TLC to residual volume [94-96]. Like spirometry, oscillometry is potentially affected by upper airway artefacts, in the form of swallows, vocal cord closures, coughs, incorrect positioning of the tongue and mouth leaks (supplementary figure E1).

For all oscillometric acquisitions, patients should be breathing in a relaxed and stable manner, seated in upright posture with correct head position, cheek support, mouthpiece seal and tongue position. Therefore, careful instructions should be provided so that during the acquisition, patients breathe with the same tidal volumes and frequencies as during stable, relaxed conditions. Prior to the measurement, a quick visual check for leaks around the mouth and use of a nose clip is essential, as well as ensuring that a stable period of tidal breathing is achieved. Table 4 lists the minimum instructions and information that should be provided to the patient prior to testing.

Adequate training of clinical staff and/or researchers administering the oscillometry test is required, given the potential for artefacts to affect the final results. This is particularly important in children.

Oscillometry testing protocols will vary according to the many applications that oscillometry is suited for, e.g. infants, preschool- and school-aged children, the elderly, epidemiological studies, occupational screening and home monitoring. However, there are general principles on which an oscillometry acquisition protocol should be based, as follows.

\section{Minimum number of technically acceptable replicate measurements}

The number of technically acceptable measurements used to determine a mean value will affect the variability of the test. Work in adults suggests that two technically acceptable measurements result in the same mean resistance and reactance values as three or more replicate measurements, regardless of measurement duration [97]. There is no comparable information of the effect of the number of replicates in children. However, it is recommended to use at least three replicates, which are deemed acceptable after application of specified quality criteria: visual inspection, within-session coefficient of variability $(\mathrm{CoV})$ and automated signal processing. The replicates that are used to derive the indices should all be completely free of artefacts. Note that in some applications, artefacts may be removed prior to calculations of mean indices (see Reporting of results and Quality control sections).

It is recommended that the three replicates used to derive indices should have a CoV of $R_{\mathrm{rs}}$, at the lowest oscillation frequency of $\leqslant 10 \%$ in adults and $\leqslant 15 \%$ in children, although there are currently no published data to support these cut-offs. Use of an arbitrary $\mathrm{CoV}$ to select replicates to calculate indices will force the

TABLE 3 Key information that should be reported on signal processing in oscillometry measurements (supplementary material section E1)

\footnotetext{
Method for impedance calculation

Window length, overlap

Filtering (low and band pass) specifications

Ensemble averaging details

Breath detection method

Quality control and rejection criteria
} 
TABLE 4 Minimum instructions to be provided to subjects prior to oscillometry acquisition

Explain to the patient the duration of a single acquisition and the number of replicates that are likely to be recorded

Describe the nature of the sensations generated by the pressure oscillations, e.g. that they will sense a gentle "vibration" or "fluttering" in their mouth and chest during the measurement. A practice run before data acquisition may be useful, particularly in young children

Encouragement to be relaxed and to "breathe as normal"

Explain that an initial brief period of observation while breathing on the mouthpiece will occur before the oscillation starts, which is to ensure breathing is normal and stable before the acquisition starts

Correct head position: ask the subject to have an upright posture with a very slight "chin-up" position if seated (which should be the case for most clinical tests in adults and young children)

Avoidance of swallowing

Instruct and demonstrate how the teeth and lips should grip and maintain a firm seal on the mouthpiece to avoid leaks

Ask the patient to keep the tongue relaxed and below the mouthpiece and to not block the orifice

Instruct and demonstrate if necessary, support of the cheeks with the palm and fingers, and of the floor of the mouth with the thumb positioned below the chin. In children, cheek support must be done by staff or parents

selection of values that are close to each other, and will exclude outlying values. Use of $\mathrm{CoV}$ and its specified threshold value to select replicates should be declared in the report or methods section of publications.

While multiple replicate measurements remain the norm in laboratory testing, longer recording durations with a single measurement may be more practical and feasible in field testing or unsupervised home monitoring $[56,58]$.

\section{Duration of acquisition}

The length of acquisition during infancy will depend on the method used. For example, low-frequency oscillometry is measured during an apnoea (via the Hering-Breuer reflex) and therefore should not exceed a reasonable breath-hold time period (typically 5-8 s). However, in quietly breathing sleeping infants, there is no reason why the suggested 30 or $60 \mathrm{~s}$ collection time (to maximise the number or respiratory cycles) could not be also considered in this population.

In school-aged children, data acquisitions of $60 \mathrm{~s}$ resulted in better within-session and between-day reproducibility than $30 \mathrm{~s}, 16 \mathrm{~s}$ or $8 \mathrm{~s}$ acquisitions [98]. Longer acquisitions are likely to be more challenging in younger paediatric populations. In healthy adults and adults with asthma or COPD, within-session variability also decreased as acquisition duration increased from $16 \mathrm{~s}, 30 \mathrm{~s}$ and $60 \mathrm{~s}$ [97]. Additionally, there were small but statistically significant differences in mean $R_{\mathrm{rs}}$ or $X_{\mathrm{rs}}$, between triplicate measurements of $16 \mathrm{~s}, 30 \mathrm{~s}$ and $60 \mathrm{~s}$, in healthy adults or those with asthma or COPD [97].

A suggested minimum acquisition time that would be suitable for high-school aged children and adults is $30 \mathrm{~s}$ and for children aged $<12$ years is $16 \mathrm{~s}$. This would allow recording of at least three artefact-free breaths, but be short enough to be practical and to avoid movement or fatigue. However, there are a range of acquisition times that have been used, which has been dependent on the clinical application and the populations studied, e.g. infants and toddlers versus adults, research studies versus clinical measurements and the severity of the disease. The wide range of testing situations arising from the combinations of patient, disease and laboratory conditions implies that the duration of oscillometry acquisition will vary to suit the population being tested, with the goal of achieving reproducible measurements as described earlier. As such, the testing durations used should be stated in the laboratory report or research publication to allow replication and comparison of results.

\section{Effect of volume history}

Volume history potentially affects impedance measurements in individuals with airways disease [99-101] and in healthy subjects during bronchial challenge testing [102]. Deep inspirations have variable effects on lung function, which differ between diseases [99-101, 103-106].

Deep breaths (i.e. inflation to TLC) during testing potentially affect results in asthmatics because of the known bronchodilator effects of deep breaths in asthma [107-109]. Thus, standardisation of lung volume history is necessary. The response to deep breaths during bronchial challenge tests also differs between asthmatics and non-asthmatics [99-101]. In non-asthmatic subjects, deep breaths prior to inhalation of an 
airway smooth muscle agonist protect against airway narrowing, while deep breaths after inhalation lead to sustained airway dilation. In asthmatic subjects, deep breaths may have reduced but variable effects in protecting against airway narrowing or dilating airways post-bronchoconstriction, depending on disease state or severity [99-101]. Indeed, deep breaths can even worsen baseline airway obstruction, measured by either spirometry [110] or oscillometry [111]. Therefore, bronchial challenge using oscillometry may be more sensitive for detecting airway hyperresponsiveness, particularly when it is mild. Since oscillometry is measured during tidal breathing and without deep inspirations, the sensitivity of such tests may differ compared with tests using spirometry. However, further studies on this are needed.

Until the effects of volume history on oscillometry parameters and bronchial challenges are better characterised, oscillometric testing is recommended before tests requiring deep breaths (exhaled nitric oxide, spirometry, diffusing capacity), as well as allowing a standardised length of time during which deep breaths are withheld before performing oscillometry. The order of testing and duration of withholding of deep inspirations should be standardised locally and documented in reports and publications.

\section{Quality control: criteria for test acceptability}

The exclusion of artefacts occurring during the test (cough, glottis closure, leaks, etc.) critically impacts on the accuracy of impedance measurements. This requires quality control processes that identify common artefacts such as leaks, swallows, coughs and incorrect tongue placement. Real-time display of volume, flow and pressure traces allows the operator to identify the presence of artefacts (supplementary figure E1) $[71,74]$, which in most situations requires repeating acquisitions until at least three measurements have been recorded that are free of artefacts.

\section{Identification of artefacts}

Subjective quality control criteria include ensuring that the tidal volumes and rate during acquisition should be stable and, that there are no pauses in volume signal accompanied by zero flow, sudden changes or spikes in resistance and pressure, which may represent swallowing, breath-holds, glottic closures and mouth leaks (supplementary figure E1) [98]. A protocol with criteria for test acceptability by visual inspection should be developed for any laboratory or project, and be freely available, to ensure capture of sufficient, artefact-free replicates as stipulated in the protocol. Differing acceptability criteria for consistency of tidal rate and volume may affect mean $R_{\mathrm{rs}}$ and $X_{\mathrm{rs}}$ values, and their repeatability, particularly in disease [112] where $R_{\mathrm{rs}}$ and $X_{\mathrm{rs}}$ may be highly flow dependent. Study of the effects of varying acceptability criteria on impedance values are needed.

Windows containing negative resistances should be excluded as they are physiologically implausible. They may result from poor design of hardware or signal processing, or noise artefacts such as cough [113]. Leaks manifest as sudden large decreases in $\left|Z_{\mathrm{rs}}\right|$, although the changes in flow-time and volume-time traces may be subtle at times. Swallowing or transient airway occlusion manifest as large values of impedance at zero flow $[98,114]$. Artefact removal can be based on statistical filtering of impedance values from individual windows [20, 115] or on the basis of complete breaths [98]. The latter reflects interest in within-breath indices [116], and results in lower test variability.

Automated strategies for removing artefacts, particularly when within-breath parameters are derived, are still a topical area of research. These include use of parameters such as the flow shape index, which represents how the shape of the time course of the oscillatory flow approximates the theoretical one [117] or other criteria $[113,118]$. Laboratories and research studies may exclude individual breaths, only the affected segments, or entire recordings. Such exclusions should be reported or made readily available, as well as the exclusion criteria used.

\section{Use of coherence}

Originally, when the cross-spectra method for calculating $Z_{\mathrm{rs}}$ was used, the coherence $\left(\gamma^{2}\right)$ between flow and pressure at each frequency was commonly used to determine whether a measurement contained too many artefacts, and thus should be discarded. Coherence can be interpreted as a causality index between the input (flow) to the respiratory system and its "linearly" dependent output (pressure) [119], or vice versa. Coherence values range between 0 (no causality at all) and 1 (perfect causality), but values less than 0.90 or 0.95 were typically discarded $[3,21,120,121]$, as low coherence values can result from various processes such as poor signal-to-noise ratio, non-linearities, cardiogenic oscillations or band overlap between the excitation and spontaneous breathing waveforms. However, there are potential problems with using coherence in this manner, including 1) varied approaches used by manufacturers to calculate its value; 2) for single-frequency tracking of impedance over time, coherence is dependent on windowing [122]; 3) coherence is often reduced in disease [36], such that an arbitrary cut-off would bias results; and 4) high coherence values do not ensure the absence of artefacts or measurement errors. While low 
coherence is generally indicative of noise or artefact, because of the differences between devices and between different diseases, coherence is no longer recommended as criterion for quality control.

\section{Use of biological controls}

Use of biological controls should be standard practice in research and clinical laboratories. A biological control is a healthy non-smoking subject, e.g. a lung function scientist. First, sufficient $Z_{\mathrm{rs}}$ data (e.g. $\geqslant 10$ separate measurements) should be obtained in a relatively short time-interval (e.g. a few weeks) so that the average and confidence intervals of $Z_{\mathrm{rs}}$ are known. If a subsequent measurement is outside the confidence interval, the oscillometric system should be evaluated carefully. Manufacturers are encouraged to develop automated quality control software to assist and enhance the utility of the biological control. The weekly use of a biological control subject is recommended for oscillometry equipment that is used on a regular basis.

\section{Reporting of results \\ Reporting of measurement details}

Details of the hardware and testing procedures should be reported to allow comparison and replication (table 5). For scientific publications, this will require supplementary files for many journals, given the significant volume of detail that should be reported.

\section{Reporting acceptability and repeatability criteria}

It is important to report the number (or range) of individual recordings that are used to calculate impedance, after the rejection criteria and quality control are met. This will allow comparison and reproduction of results between laboratories. The $\mathrm{CoV}$ should also be included in the report and if the $\mathrm{CoV}$ is higher than the specified upper limit, the results should be flagged so that this is taken into account and the results may be interpreted with caution. Manufacturers must make these features available in real time to ensure that adequate data can be collected in a testing session. The laboratory qualitycontrol processes should be documented and included in research publications (table 6). Currently, there is little information on which oscillometric parameters should be included in a basic report. Such parameters should be determined by the users and manufacturers should allow flexibility in report design. However, testing protocols, quality control criteria and verification procedures should be reported. Hence figure 2 is an illustrative example only of what might be included in a report. Note that this is not a recommended reporting template. The "technical notes" might be made available in the laboratory resources, rather than appear on the laboratory report.

\section{Reference values}

There are numerous published values in different populations, for both children and adults [123] (supplementary table E1). As with all lung function tests, the appropriateness of any predicted equations for a particular oscillometric device should be determined for the population in which it is to be applied by each laboratory. There is a need to obtain normative values, including bronchodilator responses, for children and adults from different countries using standardise breathing protocols and signal analyses, from which multiethnic normative values similar to the Global Lung Function Initiative values for spirometry [124] may be derived. The possible differences in measurements between devices [10, 79, 125127] also require further study. In the absence of these data, reference values derived from a device that is most similar to the device being used is recommended. It is recommended that $\mathrm{z}$-scores for each parameter be included in the output, where the necessary statistical data are available. This avoids the problem of having a predicted value close to zero, when use of percentage predicted can become very large and problematic in terms of clinical interpretation.

\section{Children}

Standing height is the dominant predictor of $R_{\mathrm{rs}}$ [128], although sex was also an independent predictor in one report [129] of preschool- and school-aged children, but not in others [130, 131]. Most normative studies on $R_{\mathrm{rs}}$ in preschool children have observed no significant effect of weight or age on $R_{\mathrm{rr}}$. In adolescents, sex-related differences in $R_{\mathrm{rs}}$ have been observed, but were small, with predicted $R_{\mathrm{rs}}$ for females being $<5 \%$ larger than that for males $[129,132,133]$. Except for one study [134], $X_{\mathrm{rs}}$ in preschool children is described as a linear function of height (supplementary figure E2, left panel) [128, 134] and both height and sex [129]. There is a large scatter in the prediction of $R_{\mathrm{rs}}$ and $X_{\mathrm{rs}}$ at low frequency in young children, and therefore, the appropriate predicted equation for any given paediatric population should be determined for that population. In the absence of local regional or geographic data, use of the reference equations from studies in which the devices and population most closely approximate the local situation is recommended. 


\section{TABLE 5 Measurement details for reporting}

Device name, model, software version and manufacturer

Input signal frequencies

Duration of individual recordings

Number of repeats

Definition of how impedance values were derived, e.g. mean of entire recordings, whole breaths only, inspiratory or expiratory

Description of breathing protocols, e.g. specific breathing manoeuvres, tidal breathing, volume history

Use of nose clip, and method of cheek support

Head and body position

TABLE 6 Oscillometry measures to report relating to quality control (see sections Quality control: criteria for test acceptability and Reporting of results)

Strategies for artefact removal that were used, e.g. visual checks, statistical filtering, whether individual window versus complete breath removal versus entire replicate were rejected

Measurement duration

Number of replicate measurements used

Within-session coefficient of variability and the cut-off used to define acceptability

Adults

Older studies were performed with equipment that is no longer on the market and few published studies were conducted with currently available commercial devices. The most comprehensive and recent study involves multiple centres and multiple, currently available oscillometric devices [10].

\section{Bronchodilator and bronchoconstrictor responses \\ Bronchodilator responses}

Whenever possible, baseline data should be expressed as $\mathrm{z}$-scores, since raw values are dependent on height and age. Furthermore, the dose of salbutamol used to assess bronchodilation should be reported. It is still debatable whether the bronchodilator response should be expressed as relative or absolute change $[135,136]$. In children and adults, the absolute change in $R_{\mathrm{rs}}$ and $X_{\mathrm{rs}}$ is dependent on the baseline value [137], but the separation using absolute values is greater between subjects with disease and control subjects [138], compared to when relative values are used. Therefore, a z-score post-bronchodilator change has also been proposed [139], which would overcome these problems. This would require the bronchodilator responses in a healthy population to be determined, from which an upper 95th percentile could be determined for each relevant oscillometry parameter. The distribution of responses may not be normal, and arithmetic transformations, e.g. log-transformation of the ratio of post-bronchodilator to pre-bronchodilator values [140] may normalise the data.

$R_{\mathrm{rs}}$ and $X_{\mathrm{rs}}$ are both volume dependent $[95,141]$. Since bronchodilation reduces lung hyperinflation, this would also potentially increase $R_{\mathrm{rs}}$ and decrease $X_{\mathrm{rs}}$, which would be in opposite directions to the direct effects of bronchodilator on airway calibre and airway closure. Therefore, the interpretation of bronchodilator responses of $R_{\mathrm{rs}}$ and $X_{\mathrm{rs}}$ may not be straightforward and could cause some disparity with spirometry response.

Supplementary table E2 shows the published articles on bronchodilator responses in healthy children, which were chosen based on the presence of the 95th percentiles for the responses, which allowed determination of a threshold value. The thresholds for bronchodilator responsiveness are remarkably similar, which for $R_{\mathrm{rs}}$ is approximately $-40 \%$ in preschool-aged children at $4-6 \mathrm{~Hz}$ forcing frequency, $40-$ $60 \%$ for $X_{\mathrm{rs}}$ and $-80 \%$ for $\mathrm{AX}$. In older children, the threshold may be slightly lower for $R_{\mathrm{rs}}$ at approximately $-35 \%$, but similar for $X_{\mathrm{rs}}$ and $\mathrm{AX}$, at approximately $40 \%$ and $-80 \%$, respectively. Therefore, it is recommended that the thresholds for defining a positive bronchodilator response, for both adults and children, are $-40 \%$ decrease in $R_{\mathrm{rs}_{5}},+50 \%$ increase in $X_{\mathrm{rs}_{5}}$ and $-80 \%$ decrease in $\mathrm{AX}$.

Supplementary table E3 shows the published literature on bronchodilator responses in healthy adults. There are only three published articles in healthy adults, with only one with sufficient numbers to provide confident thresholds [135]. Therefore, the thresholds from this article could be used to define bronchodilator responsiveness thresholds, but the limitations of this should be recognised. More studies of 
DEPARTMENT:

HOSPITAL:

PATIENT DETAILS:

Name:

Sex:

Height $(\mathrm{cm})$

Physician:

Date of birth:

Weight (kg)

Technician:

BMI: $\quad$ Smoking history:

Age:

Ethnicity:

Date of testing:

Time of testing:

Forced oscillatory mechanics (hPa.s. $\mathrm{L}^{-1}$ or $\mathrm{cmH}_{2} \mathrm{O} \cdot \mathrm{s} \cdot \mathrm{L}^{-1}$ )

\begin{tabular}{|c|c|c|c|c|c|c|c|c|c|c|}
\hline & Predicted & LLN & ULN & $\begin{array}{c}\% \text { of } \\
\text { predicted }\end{array}$ & Baseline & Z Score & Post BD & Z Score & $\begin{array}{l}\text { Absolute } \\
\text { change }\end{array}$ & $\%$ Change \\
\hline \multicolumn{11}{|l|}{$\operatorname{Rrs} 5$} \\
\hline \multicolumn{11}{|c|}{ Rrs5(insp) } \\
\hline \multicolumn{11}{|c|}{ Rrs11 } \\
\hline \multicolumn{11}{|c|}{ Rrs19 } \\
\hline \multicolumn{11}{|c|}{ Rrs5-19 } \\
\hline \multicolumn{11}{|l|}{ Xrs5 } \\
\hline \multicolumn{11}{|c|}{ Xrs5(insp) } \\
\hline \multicolumn{11}{|c|}{ Xrs11 } \\
\hline \multicolumn{11}{|l|}{ Xrs19 } \\
\hline \multicolumn{11}{|l|}{$A X$} \\
\hline \multicolumn{11}{|l|}{ Fres } \\
\hline \multicolumn{6}{|c|}{ Tidal vol: pre-BD: } & \multicolumn{5}{|c|}{ Resp rate: pre-BD: } \\
\hline
\end{tabular}

Reference values are those of $X X$ et al and of $Y Y$ et al.

Bronchodilator: (Drug and dose)

A significant change in $\mathrm{Rrs}$ with bronchodilator is $\mathrm{XX} \mathrm{hPa} \cdot \mathrm{S} \cdot \mathrm{L}^{-1}$ or $\mathrm{cmH}_{2} \mathrm{O} \cdot \mathrm{S} \cdot \mathrm{L}^{-1}$ or $\mathrm{XX} \%$ of baseline (reference)

A significant change in Xrs with bronchodilator is $\mathrm{XX} \mathrm{hPa \cdot s} \cdot \mathrm{L}^{-1}$ or $\mathrm{cmH}_{2} \mathrm{O} \cdot \mathrm{s} \cdot \mathrm{L}^{-1}$ or $\mathrm{XX} \%$ of baseline (reference)

Respiratory scientist's/technician's/therapist's comments: including number of acquisitions made, how many were used and the coefficient of variation of Rrs5. Any difficulties with testing can be noted here, e.g. difficulty with mouth seal, tongue position, cheek support, etc.

Graphs of Rrs and Xrs. Graphs should show Rrs and Xrs versus oscillation

frequency. 95\% confidence intervals would also ideally be shown on the graphs

\begin{tabular}{|l|}
\hline Clinical details: reason for test \\
\hline Physician's report: \\
\\
\hline
\end{tabular}

Technical notes: (this section could be made available offline)

Device manufacturer, model, firmware release number:

Filter model:

Acquisition and Quality Control: (1) minimum number of acquisition - XX of Xs, (2) artefact identification by XXX, (3) artefacts were handled by XXXX

Parameter calculation: average of at least 3 acquisitions of coefficent of variation $\leqslant 10 \%$ (adults) and $15 \%$ (children).

Verification: daily impedance verfication $\left(\leqslant \pm 10 \%\right.$ or $\pm 0.1 \mathrm{hPa} \cdot \mathrm{s} \cdot \mathrm{L}^{-1}$, whichever is greater). Loads used and date and time of last verification.

Signal processing: (method of impedance calculation, window length, overlap, filtering, ensemble averaging, breath

detection method, method of $A X$ calculation.)

$\begin{array}{lcccccc}\text { Serial values: } & \text { Rrs5 } & \text { Z-score } & \text { Rrs5 } \\ \text { Date: } & \text { (pre-BD) } & & \text { (post-BD) } & \text { Z-score } & \begin{array}{c}\text { Xrs5 } \\ \text { (pre-BD) }\end{array} & \text { Z-score } \\ \text { (post-BD) } & \text { Z-score }\end{array}$

FIGURE 2 Illustrative example of a oscillometry pulmonary function test report. Note that the oscillometry parameters included in a report should be determined by end-users. NB: the parameters in this example report are not a recommendation of which ones to report. BMI: body mass index; LLN: lower limit of normal; ULN: upper limit of normal; BD: bronchodilator; $R_{\text {rs }}$ : respiratory system resistance; $X_{\text {rs }}$ : respiratory system reactance; $A X$ : area of reactance; $f_{\text {res }}$ : resonant frequency. 
bronchodilator responsiveness in healthy children and adults are therefore required, both to provide better validation, comparison between populations and between devices and to allow definition of thresholds based on $\mathrm{z}$-scores.

\section{Bronchial challenge testing}

Oscillometry is an alternative to spirometry for conducting bronchial challenge testing in adults [9, 27-38] and children [39-45]. However, particularly in children, there may be underestimation of the change in $R_{\mathrm{rs}}$ during challenge testing due to upper airway artefact and wall shunting [46]. This effect may be reduced by using admittance $\left(1 / Z_{\mathrm{rs}}\right)$ instead of $R_{\mathrm{rs}}[47,142]$.

So-called cut-offs for oscillometry during bronchial challenge testing have been determined in older children and adults, by referencing the standard cut-offs from spirometry (supplementary table E4). However, potentially better cut-offs to define normality could be derived from studies of general population samples, without reference to spirometry gold standards. Such cut-offs could have better clinical utility than spirometry-based tests. Airway hyperresponsiveness measured by oscillometry is reproducible $[28,30,41,143]$ and is correlated with responsiveness measured by forced expiratory volume in $1 \mathrm{~s}\left(\mathrm{FEV}_{1}\right)$.

The sensitivity and specificity of suggested cut-offs for a positive challenge test using $R_{\mathrm{rs}}$, $X_{\mathrm{rs}}$, respiratory system conductance and dose-response slopes, for a number of different forcing frequencies, can be calculated for the published studies (supplementary table E4). There is a wide variability across studies, which may be explained by differences in methods used and differences in study populations. It is unlikely that differences in measurements between different devices significantly affect the measurements of airway hyperresponsiveness, but direct comparisons (i.e. replicate challenges with different oscillometry devices) have not been made. Given this variability, it is currently recommended that local thresholds should be developed which would be appropriate for the specific population with a specific device.

There is some discordance in detecting airway hyperresponsiveness between bronchial challenges performed with oscillometry versus with challenges performed with spirometry, in which case changes in oscillometry indices may provide additional information to spirometry. For example, some subjects report symptoms during the challenge test without accompanying changes in $\mathrm{FEV}_{1}$ but have changes in $R_{\mathrm{rs}}$ and $\mathrm{AX}$, which suggests airway narrowing and closure $[144,145]$. This disparity between spirometry and impedance changes are likely related to differences in volume history (Effect of volume history section). In obese asthmatic and non-asthmatic individuals, bronchial challenge is associated with greater expiratory flow limitation measured by $X_{\mathrm{rs}}$. This measurement was shown to correlate better with symptoms than did $\mathrm{FEV}_{1}[146]$.

\section{Future research to improve the technical performance of oscillometry}

More research on quality control methods for oscillometric parameters and their effects on repeatability, across various age ranges and in different respiratory diseases and clinical settings, e.g. the intensive care setting and population screening will further improve the quality and standardisation of measurements. This may include studies of tidal volume and rate, automated detection of artefacts, effects of CoV cut-offs and effects of gas mixtures and ventilation hardware in the intensive care unit. Large studies to determine multiethnic population normal values, equivalent to the Global Lung Initiative values for spirometry [124] are needed. Dynamic impedance, similar to the waveforms used for spirometry validation, should be developed and could be used to standardise oscillometry devices.

Improving the performance standards of oscillometry devices, standardising and improving the way in which it is administered, and improving the quality control of the final measurements, will increase the overall quality of impedance measurements in the clinical and research settings. Hence, the authors are of the strong belief that this will allow the benefits of oscillometry in medicine to be realised.

Conflict of interest: G.G. King reports grants from American Thoracic Society and European Respiratory Society, during the conduct of the study; a collaborative research agreement and IP agreement with Restech, grants and personal fees for lectures from AstraZeneca, Boehringer Ingelheim, GlaxoSmithKline, Menarini, MundiPharma and Cyclomedica, grants from NH\&MRC, Philanthropic Societies, Sydney University, outside the submitted work. J. Bates is a minor shareholder and received personal fees for advisory board work from Oscillavent, LLC, outside the submitted work; and has a patent (patent application US 20160007882 A1; proposes the use of oscillometry in ventilated patients) pending to none, and a patent PCT application WO2015127377 A1 (proposes variable tidal volume ventilation as a means of performing oscillometry in ventilated patients) pending to none. K.I. Berger has nothing to disclose. P. Calverley has advised Philips Respironics about the clinical application of FOT and spoken on this topic at meetings supported by this company. P.L. de Melo has a patent 28727 issued. R.L. Dellacà has a patent on the detection of EFL by FOT with royalties paid to Philips Respironics and Restech srl, a patent on monitoring lung volume recruitment by FOT with royalties paid to Vyaire, and a patent on early detection of exacerbations by home monitoring of FOT with royalties paid to Restech, and 
is co-founder and shareholder of Restech srl, a spin-off company of the Politecnico di Milano University producing medical devices for lung function testing based on FOT. R. Farré reports contracts for bench assessment of CPAP devices from Resmed and ANTADIR, outside the submitted work. G.L. Hall reports grants from American Thoracic Society and European Respiratory Society, during the conduct of the study. I. Ioan has nothing to disclose. C.G. Irvin reports other for advisory board work from Methapharm, personal fees and non-financial support for advisory board work from Medical Graphics Corp, grants from NIH and American Lung Association, outside the submitted work. D. W. Kaczka reports grants from US Department of Defense (W81XWH-16-1-0434) and National Institutes of Health (R01-HL112986, R01-HL126838 and R41-HL140640), and is co-founder and shareholder from OscillaVent, Inc., during the conduct of the study; grants from ZOLL Medical Corporation, and is shareholder and member of an advisory board for Monitor Mask, Inc., outside the submitted work; and has a patent Systems and methods for multi-frequency oscillator ventilation pending to OscillaVent, Inc. (US20160339191A1), a patent Treatment of respiratory condition using targeted delivery pending (US20150290418A1), a patent System and method for setting positive end expiratory pressure during mechanical ventilation based on dynamic lung function (US20070240717A1, abandoned), a patent Enhanced ventilation waveform device issued (US 6,435,182 B1), and a patent Servo-controlled pneumatic pressure oscillator for respiratory impedance measurements and high-frequency ventilation (US20070006924A1, abandoned). D. A. Kaminsky reports personal fees for lectures from MGC Diagnostics, Inc., outside the submitted work. H. Kurosawa reports grants and personal fees from Chest M.I. Inc., during the conduct of the study; personal fees from Nippon Boehringer Ingelheim Co. Ltd, outside the submitted work; and has a patent US2012101400 with royalties paid to Tohoku University. E. Lombardi reports personal fees from Angelini, Boehringer, GSK, Omron and Vifor, grants and personal fees from Chiesi, Lusofarmaco and Novartis, grants and non-financial support from ResTech, personal fees and non-financial support from Vertex, outside the submitted work. G.N. Maksym reports financial support from Thorasys, Thoracic Medical Systems Inc, prior to the submitted work and non-financial support from Thorasys during the submitted work; and has a patent Respiratory Device (design patent) issued to Thorasys, a patent Respiratory Device filter issued to Thorasys, a patent Piezoelectric beam bending actuated Device for measuring respiratory system impedance issued to Thorasys, and a patent Method of assessment of airway variability in airway hyperresponsiveness issued to Thorasys. F. Marchal has nothing to disclose. B.W. Oppenheimer has nothing to disclose. S.J. Simpson has nothing to disclose. C. Thamrin has a patent WO 2006130922 A1 issued which is broadly relevant to the work, and has intellectual property arrangements with Thorasys Medical Systems and Restech srl relating to research collaborations, but does not have any financial relationships with either company. M. van den Berge reports grants paid to the university from AstraZeneca, TEVA, GSK and Chiesi, outside the submitted work. E. Oostveen has nothing to disclose.

Support statement: This work was funded by the European Respiratory Society and the American Thoracic Society.

\section{References}

1 Oostveen E, MacLeod D, Lorino $\mathrm{H}$, et al. The forced oscillation technique in clinical practice: methodology, recommendations and future developments. Eur Respir J 2003; 22: 1026-1041.

2 Dubois A, Brody A, Lewis D, et al. Oscillation mechanics of lungs and chest in man. J Appl Physiol 1956; 8: 587-594.

3 Kaczka DW, Ingenito EP, Suki B, et al. Partitioning airway and lung tissue resistances in humans: effects of bronchoconstriction. J Appl Physiol 1997; 82: 1531-1541.

4 Kaczka DW, Lutchen KR. Servo-controlled pneumatic pressure oscillator for respiratory impedance measurements and high-frequency ventilation. Ann Biomed Eng 2004; 32: 596-608.

5 Hantos Z, Daróczy B, Suki B, et al. Forced oscillatory impedance of the respiratory system at low frequencies. J Appl Physiol 1986; 60: 123-132.

6 Frey U, Suki B, Kraemer R, et al. Human respiratory input impedance between 32 and $800 \mathrm{~Hz}$, measured by interrupter technique and forced oscillations. J Appl Physiol 1997; 82: 1018-1023.

7 Otis AB, McKerrow CB, Bartlett RA, et al. Mechanical factors in distribution of pulmonary ventilation. $J$ Appl Physiol 1956; 8: 427-443.

8 Bhansali PV, Irvin CG, Dempsey JA, et al. Human pulmonary resistance: effect of frequency and gas physical properties. J Appl Physiol Respir Environ Exerc Physiol 1979; 47: 161-168.

9 Wesseling GJ, Vanderhoven-Augustin IM, Wouters EF. Forced oscillation technique and spirometry in cold air provocation tests. Thorax 1993; 48: 254-259.

10 Oostveen E, Boda $\mathrm{K}$, van der Grinten $\mathrm{CP}$, et al. Respiratory impedance in healthy subjects: baseline values and bronchodilator response. Eur Respir I 2013; 42: 1513-1523.

11 Sly PD, Hayden MJ, Peták F, et al. Measurement of low-frequency respiratory impedance in infants. Am J Respir Crit Care Med 1996; 154: 161-166.

12 Hall GL, Hantos Z, Peták F, et al. Airway and respiratory tissue mechanics in normal infants. Am J Respir Crit Care Med 2000; 162: 1397-1402.

13 Hall GL, Hantos Z, Wildhaber JH, et al. Contribution of nasal pathways to low frequency respiratory impedance in infants. Thorax 2002; 57: 396-399.

14 Frey U, Makkonen $\mathrm{K}$, Wellman $\mathrm{T}$, et al. Alterations in airway wall properties in infants with a history of wheezing disorders. Am J Respir Crit Care Med 2000; 161: 1825-1829.

15 Frey U, Silverman M, Kraemer R, et al. High-frequency respiratory input impedance measurements in infants assessed by the high speed interrupter technique. Eur Respir J 1998; 12: 148-158.

16 Kjeldgaard JM, Hyde RW, Speers DM, et al. Frequency dependence of total respiratory resistance in early airway disease. Am Rev Respir Dis 1976; 114: 501-508.

17 Downie SR, Salome CM, Verbanck S, et al. Effect of methacholine on peripheral lung mechanics and ventilation heterogeneity in asthma. J Appl Physiol 2013; 114: 770-777.

18 Lutchen KR, Hantos Z, Peták F, et al. Airway inhomogeneities contribute to apparent lung tissue mechanics during constriction. J Appl Physiol 1996; 80: 1841-1849.

19 Bhatawadekar SA, Leary D, Maksym GN. Modelling resistance and reactance with heterogeneous airway narrowing in mild to severe asthma. Can J Physiol Pharmacol 2015; 93: 207-214. 
Thorpe CW, Salome CM, Berend N, et al. Modeling airway resistance dynamics after tidal and deep inspirations. J Appl Physiol 2004; 97: 1643-1653.

21 Kaczka DW, Ingenito EP, Israel E, et al. Airway and lung tissue mechanics in asthma. Effects of albuterol. Am $J$ Respir Crit Care Med 1999; 159: 169-178.

22 Bates JHT. The role of airway shunt elastance on the compartmentalization of respiratory system impedance. J Eng Sci Med Diagn Ther 2019; 2: 011001-011008.

23 Maes H, Zivanovic M, Schoukens J, et al. Estimating respiratory impedance at breathing frequencies using regularized least squares on forced oscillation technique measurements. IEEE Trans Instrum Meas 2017; 66: 479-491.

24 Hantos Z, Czövek D, Gyurkovits Z, et al. Assessment of respiratory mechanics with forced oscillations in healthy newborns. Pediatr Pulmonol 2015; 50: 344-352.

25 Gray D, Czövek D, Smith E, et al. Respiratory impedance in healthy unsedated South African infants: effects of maternal smoking. Respirology 2015; 20: 467-473.

26 Gray D, Willemse L, Visagie A, et al. Determinants of early-life lung function in African infants. Thorax 2017; 72: 445-450.

27 Bohadana AB, Peslin R, Megherbi SE, et al. Dose-response slope of forced oscillation and forced expiratory parameters in bronchial challenge testing. Eur Respir J 1999; 13: 295-300.

28 Broeders ME, Molema J, Hop WC, et al. Bronchial challenge, assessed with forced expiratory manoeuvres and airway impedance. Respir Med 2005; 99: 1046-1052.

29 Imahashi Y, Kanazawa H, Ijiri N, et al. Analysis of the contributing factors to airway hyperresponsiveness by a forced oscillation technique in patients with asthma. Osaka City Med J 2014; 60: 53-62.

30 McClean MA, Htun C, King GG, et al. Cut-points for response to mannitol challenges using the forced oscillation technique. Respir Med 2011; 105: 533-540.

31 Naji N, Keung E, Kane J, et al. Comparison of changes in lung function measured by plethymography and IOS after bronchoprovocation. Respir Med 2013; 107: 503-510.

32 Rozen D, Bracamonte M, Sergysels R. Comparison between plethysmographic and forced oscillation techniques in the assessment of airflow obstruction. Respiration 1983; 44: 197-203.

33 Schmekel B, Smith HJ. The diagnostic capacity of forced oscillation and forced expiration techniques in identifying asthma by isocapnic hyperpnoea of cold air. Eur Respir J 1997; 10: 2243-2249.

34 Suzuki S, Chonan T, Sasaki H, et al. Time-course of response in exercise-induced bronchoconstriction. Ann Allergy 1984; 53: 341-346.

35 van Noord JA, Clement J, van de Woestijne KP, et al. Total respiratory resistance and reactance as a measurement of response to bronchial challenge with histamine. Am Rev Respir Dis 1989; 139: 921-926.

36 Wouters EF, Polko AH, Schouten HJ, et al. Contribution of impedance measurement of the respiratory system to bronchial challenge tests. J Asthma 1988; 25: 259-267.

37 Mansur AH, Manney S, Ayres JG. Methacholine-induced asthma symptoms correlate with impulse oscillometry but not spirometry. Respir Med 2008; 102: 42-49.

38 Tsurikisawa N, Oshikata C, Tsuburai T, et al. Physiologic airway responses to inhaled histamine and acetylcholine in patients with mild asthma as analyzed by forced oscillation. Arerugi 2015; 64: 952-970.

39 Alblooshi AS, Simpson SJ, Stick SM, et al. The safety and feasibility of the inhaled mannitol challenge test in young children. Eur Respir J 2013; 42: 1420-1423.

40 Bisgaard H, Klug B. Lung function measurement in awake young children. Eur Respir J 1995; 8: $2067-2075$.

41 Hall GL, Gangell C, Fukushima T, et al. Application of a shortened inhaled adenosine-5'-monophosphate challenge in young children using the forced oscillation technique. Chest 2009; 136: 184-189.

42 Kalliola S, Malmberg LP, Kajosaari M, et al. Assessing direct and indirect airway hyperresponsiveness in children using impulse oscillometry. Ann Allergy Asthma Immunol 2014; 113: 166-172.

43 Malmberg LP, Mäkelä MJ, Mattila PS, et al. Exercise-induced changes in respiratory impedance in young wheezy children and nonatopic controls. Pediatr Pulmonol 2008; 43: 538-544.

44 Nielsen KG, Bisgaard H. The effect of inhaled budesonide on symptoms, lung function and cold air and methacholine responsivenesss in 2- to 5-year-old asthmatic children. Am J Respir Crit Care Med 2000; 162: 1500-1506.

45 Schulze J, Smith HJ, Fuchs J, et al. Methacholine challenge in young children as evaluated by spirometry and impulse oscillometry. Respir Med 2012; 106: 627-634.

46 Marchal F, Mazurek H, Habib M, et al. Input respiratory impedance to estimate airway hyperreactivity in children: standard method versus head generator. Eur Respir J 1994; 7: 601-607.

47 Simpson SJ, Straszek SP, Sly PD, et al. Clinical investigation of respiratory system admittance in preschool children. Pediatr Pulmonol 2012; 47: 53-58.

48 Boeyen J, Callan AC, Blake D, et al. Investigating the relationship between environmental factors and respiratory health outcomes in school children using the forced oscillation technique. Int J Hyg Environ Health 2017; 220: 494-502.

49 Pasker HG, Peeters M, Genet P, et al. Short-term ventilatory effects in workers exposed to fumes containing zinc oxide: comparison of forced oscillation technique with spirometry. Eur Respir J 1997; 10: 1523-1529.

50 Pham QT, Bourgkard E, Chau N, et al. Forced oscillation technique (FOT): a new tool for epidemiology of occupational lung diseases? Eur Respir J 1995; 8: 1307-1313.

51 Skloot G, Goldman M, Fischler D, et al. Respiratory symptoms and physiologic assessment of ironworkers at the World Trade Center disaster site. Chest 2004; 125: 1248-1255.

52 Oppenheimer BW, Goldring RM, Herberg ME, et al. Distal airway function in symptomatic subjects with normal spirometry following World Trade Center dust exposure. Chest 2007; 132: 1275-1282.

53 Friedman SM, Maslow CB, Reibman J, et al. Case-control study of lung function in World Trade Center Health Registry area residents and workers. Am J Respir Crit Care Med 2011; 184: 582-589.

54 Berger KI, Turetz M, Liu M, et al. Oscillometry complements spirometry in evaluation of subjects following toxic inhalation. ERJ Open Res 2015; 1: 00043-02015.

55 Jordan HT, Friedman SM, Reibman J, et al. Risk factors for persistence of lower respiratory symptoms among community members exposed to the 2001 World Trade Center terrorist attacks. Occup Environ Med 2017; 74: $449-455$. 
Dellacà RL, Gobbi A, Pastena M, et al. Home monitoring of within-breath respiratory mechanics by a simple and automatic forced oscillation technique device. Physiol Meas 2010; 31: N11-N24.

Rigau J, Farré R, Roca J, et al. A portable forced oscillation device for respiratory home monitoring. Eur Respir J 2002; 19: 146-150.

Timmins SC, Diba C, Thamrin C, et al. The feasibility of home monitoring of impedance with the forced oscillation technique in chronic obstructive pulmonary disease subjects. Physiol Meas 2013; 34: 67-81.

Gobbi A, Dellacà R, King GG, et al. Towards predicting individual risk in asthma using daily home monitoring of resistance. Am J Respir Crit Care Med 2017; 195: 265-267.

Walker PP, Pompilio PP, Zanaboni P, et al. Telemonitoring in chronic obstructive pulmonary disease (CHROMED). A randomized clinical trial. Am J Respir Crit Care Med 2018; 198: 620-628.

Kaczka DW, Ingenito EP, Body SC, et al. Inspiratory lung impedance in COPD: effects of PEEP and immediate impact of lung volume reduction surgery. J Appl Physiol 2001; 90: 1833-1841.

Navajas D, Farré R, Canet J, et al. Respiratory input impedance in anesthetized paralyzed patients. J Appl Physiol 1990; 69: 1372-1379.

Lorx A, Suki B, Hercsuth M, et al. Airway and tissue mechanics in ventilated patients with pneumonia. Respir Physiol Neurobiol 2010; 171: 101-109.

Kaczka DW, Ingenito EP, Lutchen KR. Technique to determine inspiratory impedance during mechanical ventilation: implications for flow limited patients. Ann Biomed Eng 1999; 27: 340-355.

impedance. J Appl Physiol 1993; 75: 478-488.

Lutchen KR. Optimal selection of frequencies for estimating parameters from respiratory impedance data. IEEE Trans Biomed Eng 1988; 35: 607-617.

Suki B, Lutchen KR. Pseudorandom signals to estimate apparent transfer and coherence functions of nonlinear systems: applications to respiratory mechanics. IEEE Trans Biomed Eng 1992; 39: 1142-1151.

Zannin E, Chakrabarti B, Govoni L, et al. Detection of expiratory flow limitation by forced oscillations during non-invasive ventilation. Am J Respir Crit Care Med 2019; 200: 1063-1065.

Bates JHT, Irvin CG, Farré R, et al. Oscillation mechanics of the respiratory system. Compr Physiol 2011; 1: $1233-1272$.

Kaczka DW, Dellacá RL. Oscillation mechanics of the respiratory system: applications to lung disease. Crit Rev Biomed Eng 2011; 39: 337-359.

Horowitz JG, Siegel SD, Primiano FP, et al. Computation of respiratory impedance from forced sinusoidal oscillations during breathing. Comput Biomed Res 1983; 16: 499-521.

Oppenheimer BW, Goldring RM, Berger KI. Distal airway function assessed by oscillometry at varying respiratory rate: comparison with dynamic compliance. COPD 2009; 6: 162-170.

Michaelson ED, Grassman ED, Pete
J Clin Invest 1975; 56: 1210-1230.

Daróczy B, Hantos Z. Generation of optimum pseudorandom signals for respiratory impedance measurements. Int J Biomed Comput 1990; 25: 21-31.

Droczy B, Fabula A, Hantos Z. Use of noninteger-multiple pseudorandom excitation to minimize nonlinear effects on impedance estimation. Eur Respir Rev 1991; 1: 183-187.

Suki B, Hantos Z, Daróczy B, et al. Nonlinearity and harmonic distortion of dog lungs measured by low-frequency forced oscillations. J Appl Physiol 1991; 71: 69-75.

Gomes RFM, Shen X, Ramchandani R, et al. Comparative respiratory system mechanics in rodents. J Appl Physiol 2000; 89: 908-916.

Zhang Q, Suki B, Lutchen KR. Harmonic distortion from nonlinear systems with broadband inputs: Applications to lung mechanics. Ann Biomed Eng 1995; 23: 672-681.

Hellinckx J, Cauberghs M, De Boeck K, et al. Evaluation of impulse oscillation system: comparison with forced oscillation technique and body plethysmography. Eur Respir J 2001; 18: 564-570.

Delavault E, Saumon G, Georges R. Identification of transducer defect in respiratory impedance measurements by forced random noise. Correction of experimental data. Respir Physiol 1980; 40: 107-117.

Navajas D, Duvivier C, Farré R, et al. A simplified method for monitoring respiratory impedance during continuous positive airway pressure. Eur Respir J 2000; 15: 185-191.

Peslin R, Jardin P, Duvivier C, et al. In-phase rejection requirements for measuring respiratory input impedance. J Appl Physiol Respir Environ Exerc Physiol 1984; 56: 804-809.

Farré R, Navajas D, Peslin R, et al. A correction procedure for the asymmetry of differential pressure transducers in respiratory impedance measurements. IEEE Trans Biomed Eng 1989; 36: 1137-1140.

Farré R, Peslin R, Navajas D, et al. Analysis of the dynamic characteristics of pressure transducers for studying respiratory mechanics at high frequencies. Med Biol Eng Comput 1989; 27: 531-537. calibrated according to the manufacturer's instructions. Am J Respir Crit Care Med 2018; 197: 532-534.

Calverley PMA, Farre R. Putting noninvasive lung mechanics into context. Eur Respir J 2013; 42: 1435-1437.

Miller MR, Hankinson J, Brusasco V, et al. Standardisation of spirometry. Eur Respir J 2005; 26: 319-338.

Isetta V, Montserrat JM, Santano R, et al. Novel approach to simulate sleep apnea patients for evaluating positive pressure therapy devices. PLoS One 2016; 11: e0151530.

Farré R, Navajas D, Montserrat JM. Technology for noninvasive mechanical ventilation: looking into the black box. ERJ Open Res 2016; 2: 00004-2016.

Wanger J, Clausen JL, Coates A, et al. Standardisation of the measurement of lung volumes. Eur Respir J 2005; 26: $511-522$.

Dionísio GH, dos Santos DO, Perossi L, et al. The influence of different mouthpieces on impulse oscillometry results. Respir Care 2018; 63: 565-572.

Thamrin C, Frey U. Effect of bacterial filter on measurement of interrupter resistance in preschool and school-aged children. Pediatr Pulmonol 2008; 43: 781-787.

Beydon N, Davis SD, Lombardi E, et al. An official American Thoracic Society/European Respiratory Society statement: pulmonary function testing in preschool children. Am J Respir Crit Care Med 2007; 175: 1304-1345. 
Brown NJ, Salome CM, Berend N, et al. Airway distensibility in adults with asthma and healthy adults, measured by forced oscillation technique. Am J Respir Crit Care Med 2007; 176: 129-137.

95 Kelly VJ, Brown NJ, Sands SA, et al. Effect of airway smooth muscle tone on airway distensibility measured by the forced oscillation technique in adults with asthma. J Appl Physiol 2012; 112: 1494-1503.

Mailhot-Larouche S, Lachance M, Bullone M, et al. Assessment of airway distensibility by the forced oscillation technique: reproducible and potentially simplifiable. Front Physiol 2017; 8: 223.

Watts JC, Farah CS, Seccombe LM, et al. Measurement duration impacts variability but not impedance measured by the forced oscillation technique in health, asthma and COPD subjects. ERJ Open Res 2016; 2: 00094-2015.

98 Robinson PD, Turner M, Brown NJ, et al. Procedures to improve the repeatability of forced oscillation measurements in school-aged children. Respir Physiol Neurobiol 2011; 177: 199-206.

99 Jensen A, Atileh H, Suki B, et al. Selected contribution: airway caliber in healthy and asthmatic subjects: effects of bronchial challenge and deep inspirations. J Appl Physiol 2001; 91: 506-515.

100 Salome CM, Thorpe CW, Diba C, et al. Airway re-narrowing following deep inspiration in asthmatic and nonasthmatic subjects. Eur Respir J 2003; 22: 62-68.

101 Slats AM, Janssen K, van Schadewijk A, et al. Bronchial inflammation and airway responses to deep inspiration in asthma and chronic obstructive pulmonary disease. Am J Respir Crit Care Med 2007; 176: 121-128.

102 Oostveen E, Peslin R, Gallina C, et al. Flow and volume dependence of respiratory mechanical properties studied by forced oscillation. J Appl Physiol 1989; 67: 2212-2218.

103 Chapman DG, Berend N, King GG, et al. Deep inspirations protect against airway closure in nonasthmatic subjects. J Appl Physiol 2009; 107: 564-569.

104 Orehek J, Nicoli MM, Delpierre S, et al. Influence of the previous deep inspiration on the spirometric measurement of provoked bronchoconstriction in asthma. Am Rev Respir Dis 1981; 123: 269-272.

105 Scichilone N, La Sala A, Bellia M, et al. The airway response to deep inspirations decreases with COPD severity and is associated with airway distensibility assessed by computed tomography. J Appl Physiol 2008; 105: 832-838.

106 Skloot G, Schechter C, Desai A, et al. Impaired response to deep inspiration in obesity. J Appl Physiol 2011; 111: 726-734.

107 Pellegrino R, Sterk PJ, Sont JK, et al. Assessing the effect of deep inhalation on airway calibre: a novel approach to lung function in bronchial asthma and COPD. Eur Respir J 1998; 12: 1219-1227.

108 Skloot G, Togias A. Bronchodilation and bronchoprotection by deep inspiration and their relationship to bronchial hyperresponsiveness. Clin Rev Allergy Immunol 2003; 24: 55-72.

109 Lutchen KR, Jensen A, Atileh H, et al. Airway constriction pattern is a central component of asthma severity. the role of deep inspirations. Am J Respir Crit Care Med 2001; 164: 207-215.

110 Lim T, Ang S, Rossing T, et al. The effects of deep inhalation on maximal expiratory flow during intensive treatment of spontaneous asthmatic episodes. Am Rev Respir Dis 1989; 14: 340-343.

111 How SC, Romer LM, McConnell AK. Acute effects of inspiratory pressure threshold loading upon airway resistance in people with asthma. Respir Physiol Neurobiol 2009; 166: 159-163.

112 Nakagawa M, Hattori N, Haruta Y, et al. Effect of increasing respiratory rate on airway resistance and reactance in COPD patients. Respirology 2015; 20: 87-94.

113 Bhatawadekar SA, Leary D, Chen Y, et al. A study of artifacts and their removal during forced oscillation of the respiratory system. Ann Biomed Eng 2013; 41: 990-1002.

114 Que CL, Kenyon CM, Olivenstein R, et al. Homeokinesis and short-term variability of human airway caliber. J Appl Physiol 2001; 91: 1131-1141.

115 Schweitzer C, Chone C, Marchal F. Influence of data filtering on reliability of respiratory impedance and derived parameters in children. Pediatr Pulmonol 2003; 36: 502-508.

116 Dellacà R, Santus P, Aliverti A, et al. Detection of expiratory flow limitation in COPD using the forced oscillation technique. Eur Respir J 2004; 23: 232-240.

117 Marchal F, Schweitzer C, Demoulin B, et al. Filtering artefacts in measurements of forced oscillation respiratory impedance in young children. Physiol Meas 2004; 25: 1153-1166.

118 Pham TT, Thamrin C, Robinson PD, et al. Respiratory artefact removal in forced oscillation measurements: a machine learning approach. IEEE Trans Biomed Eng 2017; 64: 1679-1687.

119 Maki BE. Interpretation of the coherence function when using pseudorandom inputs to identify nonlinear systems. IEEE Trans Biomed Eng 1986; 33: 775-779.

120 Hantos Z, Daróczy B, Suki B, et al. Input impedance and peripheral inhomogeneity of dog lungs. J Appl Physiol 1992; 72: 168-178.

121 Oostveen E, Zwart A. Reliability of the coherence function for rejecting respiratory impedance data. Eur Respir Rev 1991; 1: 218-221.

122 Lorino H, Mariette C, Karouia M, et al. Influence of signal processing on estimation of respiratory impedance. J Appl Physiol 1993; 74: 215-223.

123 Kalchiem-Dekel O, Hines SE. Forty years of reference values for respiratory system impedance in adults: 19772017. Respir Med 2018; 136: 37-47.

124 Quanjer PH, Stanojevic S, Cole TJ, et al. Multi-ethnic reference values for spirometry for the 3-95-year age range: the global lung function 2012 equations. Eur Respir J 2012; 40: 1324-1343.

125 Tanimura K, Hirai T, Sato S, et al. Comparison of two devices for respiratory impedance measurement using a forced oscillation technique: basic study using phantom models. J Physiol Sci 2014; 64: 377-382.

126 Zimmermann SC, Watts JC, Bertolin A, et al. Discrepancy between in vivo and in vitro comparisons of forced oscillation devices. J Clin Monit Comput 2018; 32: 509-512.

127 Soares M, Richardson M, Thorpe J, et al. Comparison of forced and impulse oscillometry measurements: a clinical population and printed airway model study. Sci Rep 2019; 9: 2130.

128 Hellinckx J, De Boeck K, Bande-Knops J, et al. Bronchodilator response in 3-6.5 years old healthy and stable asthmatic children. Eur Respir J 1998; 12: 438-443.

129 Calogero C, Simpson SJ, Lombardi E, et al. Respiratory impedance and bronchodilator responsiveness in healthy children aged 2-13 years. Pediatr Pulmonol 2013; 48: 707-715.

130 Dencker M, Malmberg LP, Valind S, et al. Reference values for respiratory system impedance by using impulse oscillometry in children aged 2-11 years. Clin Physiol Funct Imaging 2006; 26: 247-250. 
131 Frei J, Jutla J, Kramer G, et al. Impulse oscillometry: reference values in children 100 to $150 \mathrm{~cm}$ in height and 3 to 10 years of age. Chest 2005; 128: 1266-1273.

132 Gochicoa-Rangel L, Torre-Bouscoulet L, Martínez-Briseño D, et al. Values of impulse oscillometry in healthy Mexican children and adolescents. Respir Care 2015; 60: 119-127.

133 Nowowiejska B, Tomalak W, Radliński J, et al. Transient reference values for impulse oscillometry for children aged 3-18 years. Pediatr Pulmonol 2008; 43: 1193-1197.

134 Malmberg LP, Pelkonen A, Poussa T, et al. Determinants of respiratory system input impedance and bronchodilator response in healthy Finnish preschool children. Clin Physiol Funct Imaging 2002; 22: 64-71.

135 Oostveen E, Dom S, Desager K, et al. Expression of bronchodilator response using forced oscillation technique measurements: absolute versus relative. Eur Respir J 2010; 36: 213.

136 Thamrin C, Gangell C, Kusel M, et al. Expression of bronchodilator response using forced oscillation technique measurements: absolute versus relative. Eur Respir J 2010; 36: 212-213.

137 Thamrin C, Gangell CL, Udomittipong K, et al. Assessment of bronchodilator responsiveness in preschool children using forced oscillations. Thorax 2007; 62: 814-819.

138 Oostveen E, Dom S, Desager K, et al. Lung function and bronchodilator response in 4-year-old children with different wheezing phenotypes. Eur Respir J 2010; 35: 865-872.

139 Calogero C, Parri N, Baccini A, et al. Respiratory impedance and bronchodilator response in healthy Italian preschool children. Pediatr Pulmonol 2010; 45: 1086-1094.

140 Harrison J, Gibson AM, Johnson K, et al. Lung function in preschool children with a history of wheezing measured by forced oscillation and plethysmographic specific airway resistance. Pediatr Pulmonol 2010; 45: 1049-1056.

141 Barnas GM, Sprung J, Craft TM, et al. Effect of lung volume on lung resistance and elastance in awake subjects measured during sinusoidal forcing. Anesthesiology 1993; 78: 1082-1090.

142 Nguyen YT, Demoulin B, Schweitzer C, et al. Identification of bronchodilator responsiveness by forced oscillation admittance in children. Pediatr Res 2007; 62: 348-352.

143 Choi SH, Sheen YH, Kim MA, et al. Clinical implications of oscillatory lung function during methacholine bronchoprovocation testing of preschool children. Biomed Res Int 2017; 2017: 9460190.

144 Berger KI, Kalish S, Shao Y, et al. Isolated small airway reactivity during bronchoprovocation as a mechanism for respiratory symptoms in WTC dust-exposed community members. Am J Ind Med 2016; 59: 767-776.

145 Segal LN, Goldring RM, Oppenheimer BW, et al. Disparity between proximal and distal airway reactivity during methacholine challenge. COPD 2011; 8: 145-152.

146 Mahadev S, Farah CS, King GG, et al. Obesity, expiratory flow limitation and asthma symptoms. Pulm Pharmacol Ther 2013; 26: 438-443. 